\title{
Vitiligo Caused By Chloroquine Phototoxicity
}

\section{E Selvaag}

\section{Department of Dermatology, Ullevaal Hospital, University of Oslo, Oslo, Norway}

SUMMARY: A six year old girl of Ethiopian origin suffering from atopic eczema since the age of two is presented. Prior to a visit to her grandparents in Ethiopia, she received $250 \mathrm{mg}$ chloroquine weekly as a prophylaxis against malaria. Three weeks thereafter, she developed sharply demarcated depigmented areas on the face, especially in the periorbital area. On returning home to Norway the medication was discontinued, and after a few weeks the first signs of repigmentation were noticed. Eight months after cessation of therapy, almost complete repigmentation had been achieved. Complete repigmentation was observed one year after the cessation of chloroquine-therapy.

\section{Introduction}

Pigmentation disturbances during antimalarial therapy are common. Twenty five per cent of the patients on chloroquine therapy for more than four months experience these effects (1). The intensity of the hyperpigmentation varies from bluish-black in the periorbital and other areas on the face and on the trunk, to grey over the hard palate and subungually. In addition to hyperpigmentation the bleaching of hair and freckles has been described (2), Hypopigmentation of skin during chloroquine therapy however is a rare event.

We describe a patient who developed vitiligo-like skin lesions on the face when taking chloroquine as a malariaprophylaxis, and review the literature concerning depigmentation during chloroquine therapy.

\section{Patient}

A six year old girl of Ethiopian origin but born in Norway, presented to our department in the spring of 1994 because of depigmented patches in the face. The otherwise healthy girl had since the age of two years, suffered from atopic eczema. There was no history of other skin disease in the girl or in her near family. Especially, there was no history of autoimmune skin diseases in the patient or in the family. The depigmentation had started when visiting her grandparents in Eritrea. As a prophylactic agent against malaria, she had been given $250 \mathrm{mg}$ chloroquine weekly. She received no other systemic medication nor was any topical therapy used on her face. After three weeks of antimalarial therapy the parents noticed the first skin changes in their daughter. The girl experienced no subjective complaints, played as normal. and got a lot of fresh air and sun. There were no signs of visual disturbances. In all she received ten tablets of chloroquine before returning to Norway. Here the parents discontinued the medication. After initial treatment with antimycotic ointment, she presented to our department, with the classical features of vitiligo (Fig 1). Clinical controls at one, three (Fig 2), six and eight (Fig 3) months showed a rapidly and, in the end, complete repigmentation of the previous depigmented areas.

\section{Discussion}

Hypopigmentation of skin during chloroquine treatment has been reported in only four patients (3-5). All patients were black Africans, and had been exposed to the African sun. Two patients from Ghana had been seeking medical care because of visual disturbances. Both were on selfmedication, and had been taking large amounts of chloroquine over a period of time (3). The patients had developed depigmentation on the face, especially on the cheeks, nose and brows. One also had hyperpigmentation of the hard palate. Upon cessation of the chloroquine therapy, repigmentation rapidly occurred, but the retinopathy did not

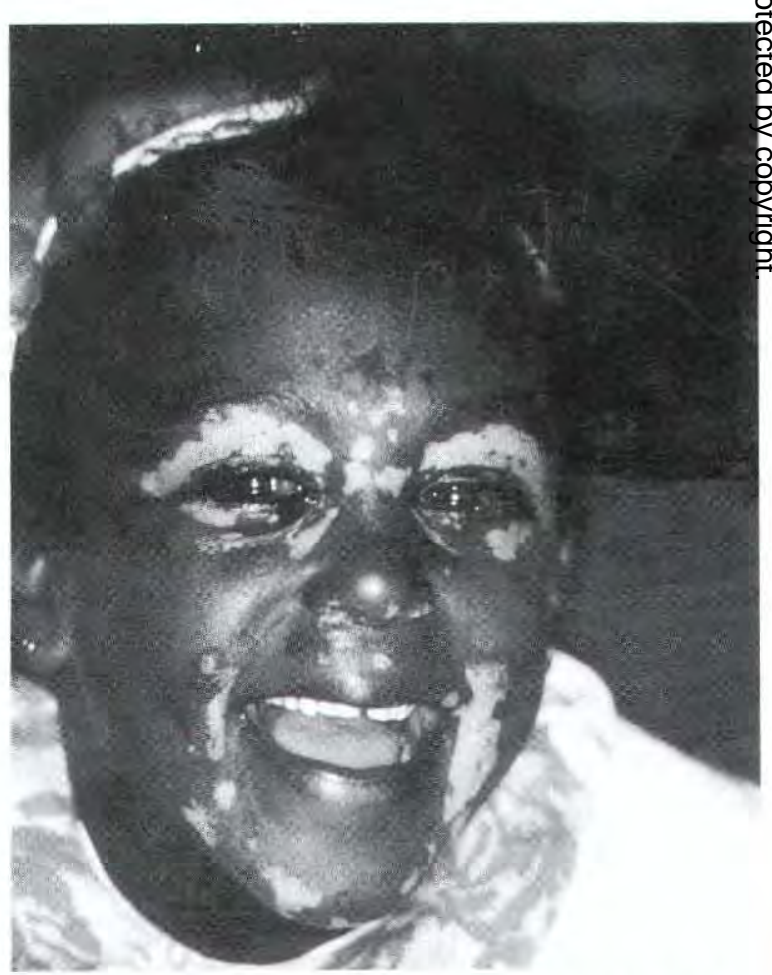

Fig 1. Depigmentation on the face, especially in the periorbital area. Note the darker areas on the glabella, indicating repigmentation only a few weeks after discontinuation of the chloroquine therapy. 
improve (3).

Another black patient, seen in The Netherlands after a trip to tropical Africa, developed facial depigmentation (4). He had been taking chloroquine as a prophylactic agent against malaria before leaving the Netherlands. After a few months in Africa, he developed a pruritic and papular rash. On investigation, the minimal erythema dose in the range about $300 \mathrm{~mm}$ was reduced. Photopatch testing with chloroquine and UVA revealed positive results.

A further patient, a black South African male, had received chloroquine since the age of 27 for rheumatoid arthritis (5). Two years after initiation of the therapy he noticed facial depigmentation. Chloroquine was discontinued and he was given vitamin $\mathrm{C}$ ( $100 \mathrm{mg}$ daily) as a placebo. After two months, complete repigmentation of the previous depigmented areas had occurred.

Interestingly, factors which influence the binding of chloroquine to melanin are those typical of cation exchange. It has been shown that the free radical content of melanin is reduced by pretreatment with ascorbic acid (6). The medication with ascorbic acid may have interfered with the drug-melanin complex and hence induced clinical improvement.

The increased chloroquine concentrations in tissues such as eye, ear, skin and hair is explained by the high affinity of the drug to melanin (7). Binding of chloroquine to melanin has been clearly established, both in vitro (8), and

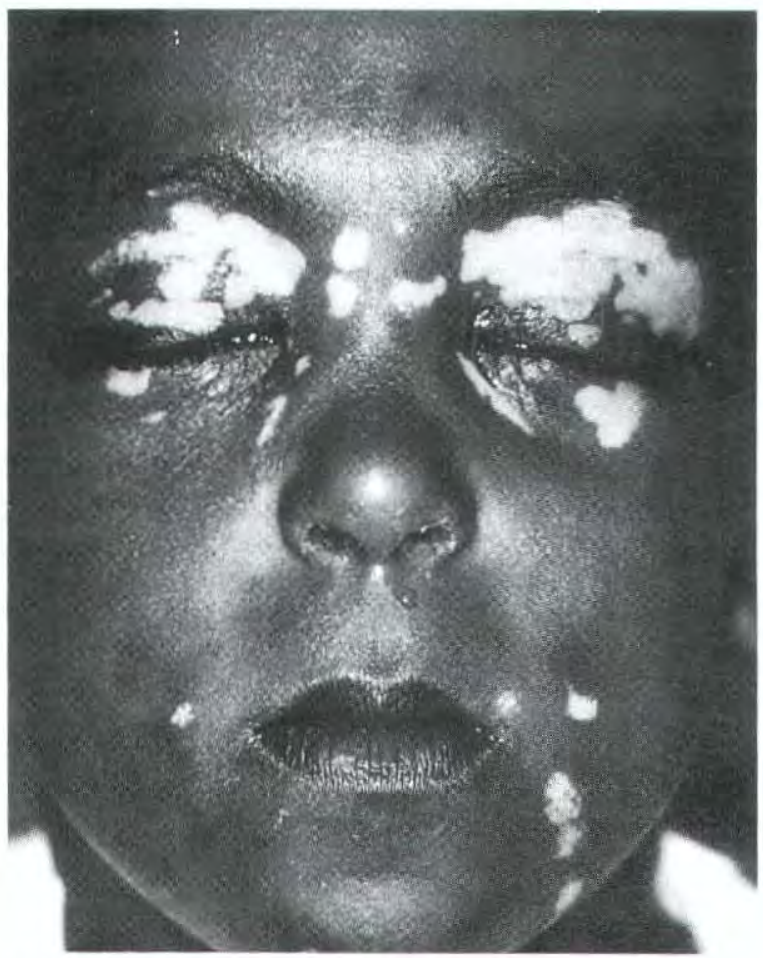

Fig 2. Rapid clinical improvement, three months after first clinical examination.

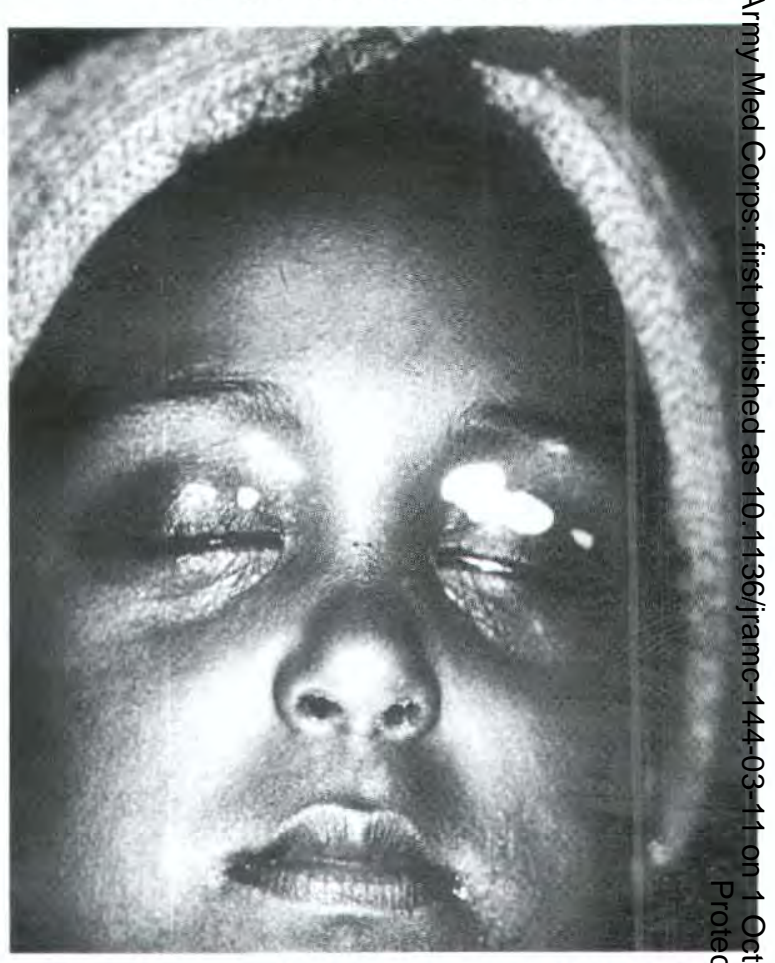

Fig 3. Almost complete repigmentation about eig $\vec{?} \overrightarrow{0}$ months after first presentation at our departmen

by whole-body radiometry in vivo (9). The theore $\$$ mechanism of the complex formation is that of cha transfer complexes (9), further hypothesis concerning pigmentation disturbances observed during chloroquin 롱 therapy, is the possible interaction between chloroquing and metals such as copper (10). The toxic effect $\frac{\Phi}{D}$ chloroquine then would be explained by interaction wit the copper-requiring enzyme tyrosinase (11). The interaction between chloroquine and melanin may explain most of the unwanted side effects of the drug, such visual disturbances, tinnitus and dizziness, hyper- an hypopigmentation. In histological investigations it h? been shown that the hyperpigmentation which occua during chloroquine therapy is due to deposition of the drus and/or hemosiderin in the skin. Deposition of chloroquin in the hair may be demonstrated as a bluish-whit fluorescence in the Wood light (12). Hypopigmentation hair has been reported in several cases, mostly in fai? haired individuals. It has been postulated that this is due t8 affinity of chloroquine for the pheomelanin complex which is more plentiful in blond and red haires individuals. This hypothesis is supported by experiment data obtained from investigations in chicks. Sams an Epstein demonstrated that installation of chloroquine int the yolk sac of red chicks induced hypopigmentation in the feathers, whereas this was not the case in black chick (13). Out of the reported cases, however, are sever individuals brunette or dark-haired $(14,15)$. One patie 
who developed hypopigmentation of the light-exposed hair also developed an increase in the generalized pigmentation. A slate grey discolouration was noticed around his eyes, on the shoulders and neck (15).

Black skin and exposure to the african sun were features that our patient had in common with the other four patients reported in the literature. Experimental results point towards a phototoxic reaction due to the ingestion of chloroquine. Whether the observed side-effect in our patient was due to the exposure to sunlight seems likely. Discontinuation of the drug therapy did not leave any residues such as scarring or permanent depigmentation. However, sun-protective precautions during therapy with antimalarial drugs would seem to be indicated.

\section{REFERENCES}

1. Dall JlC, Keane JA. Disturbances of pigmentation with chloroquine. $\mathrm{Br}$ Med J 1959; I: 1387-1389.

2. Dupre A, ORTonne J-P, Viraben R, ARFeux F. Chloroquine-induced hypopigmentation of hair and freckles. Arch Dermatol 1985; 121: 1164-1166.

3. BENTSI-ENCHILL KO. Pigmentary skin changes associated with ocular chloroquine toxicity in Ghana. Trop Geogr Med 1980; 32: 216-220.

4. WeElden HV, Bolling HH, FaIlle HBdL, Leun JCvd. Photosensitivity caused by chloroquine. Arch Dermatol 1982; 118: 290.

5. GongGryP LA, Kalla AA. Chloroquine-induced vitiligo in a patient with juvenile onset rheumatoid arthritis. Br J Rheumatol 1992; 31: 790-1.
6. BeRNSTIEN HN. Chloroquine ocular toxicity. Surv Ophthalmol 1967; 12: 415-447.

7. Dubois EL, Wallace DJ. Management of discoid and systemic lupus erythematosus. In: Wallace DJ, Dubois EL, eds. Dubois' lupus erythematosus. Philadelphia: Lea and Febiger, 1987; 501-564.

8. SAMS WM, EPSTEIN JH. The affinity of melanin for chloroquine. J Invest Dermatol 1965; 45: 482-488.

9. TJälve H, NilsSON M, LARSSON B. Studies on the binding of chlorpromazine and chloroquine to melanine in vivo. Biochem Pharmacol 1981; 30: 1845-1847.

10. BOWNESS J, MORTON R. The association of zincand other metals with melanin and a melanin-protein complex. Biochem J 1953; 53: 620.

11. Rubin M, Zvaifler N, Bernstein H, Mansour A. Chloroquine toxicity. In: Brodie B, Gillette J, eds. Drugs and enzymes. Proceedings of the Second International Pharmacological Meeting. London: Pergamon Press, $1965 ; 4: 467$.

12. Moller H. Pigmentary disturbances due to drugs. Acta Derm Venereol (Stockh) 1966; 46: 423-431.

13. Saunders TS, Fitzpatrick TB, Seiji M, Brunet P, RosenBAuM EE. Decrease in human hair color and feather pigment of fowl following chloroquine diphosphate. J Invest Dermatol 1959; 33: 87-90.

14. SHARVILL DE. Bleaching of hair by chloroquine. $\mathrm{Br} \mathrm{Mec}$ $J$ 1955; I: 1035.

15. MARriotT $P$, Borrie PF. Pigmentary changes following chloroquine. Proc R Soc Med 1975; 68: 25-26. 